\title{
Sustainable development of mining processes based on mechanochemical leaching of ore
}

\author{
Vladimir Golik ${ }^{1}$, Yuri Razorenov ${ }^{1}$, Vladimir Morkun ${ }^{2, *}$, Natalia Morkun ${ }^{2}$, and Vitalii Tron ${ }^{2}$ \\ ${ }^{1}$ North-Caucasian State Technological University, Mining Department, 44 Cosmonaut Nikolayev Str., Vladikavkaz, Russia \\ ${ }^{2}$ Kryvyi Rih National University, Automation, Computer Science and Technology Department, 11 Vitalii Matusevych Str., Kryvyi Rih, \\ Ukraine
}

\begin{abstract}
Intensive development of the mining and metallurgical complex results in considerable volumes of waste materials, more than half of which are produced by mining enterprises. Modern mining and processing can provide non-waste production only if mineral extraction and grade recovery from natural and technogenic mineral materials are regarded as a single technological process and the Earth surface preservation becomes a priority in determining parameters of process integration. The research is aimed at improving of the technology of metal leaching in a disintegrator through complex application of metallic ore concentration tailings. A radical step of reducing mining waste hazards is their utilization through introducing technogenic reserves of metallic ore concentration tailings into production, thus creating a new raw material base for the mining industry. Substantiation of the concept of non-waste utilization of off-grade mineral materials depends on the amount of integration of chemical leaching and mechanochemical activation in the disintegrator and is achieved by means of modern information technologies.
\end{abstract}

\section{Introduction}

Mineral extraction is characterized by increasing volumes and areas of mining operations aimed to satisfy humanity's growing needs [1-5]. It results in accumulation of aggressive wastes at all process stages accompanied by intensive impact on the environment causing costly preventive measures (Fig. 1).

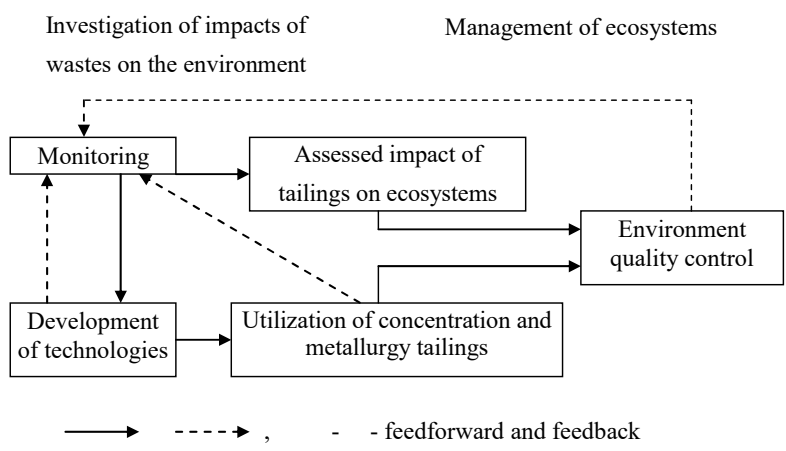

Fig. 1. Control chart of environmental conditions with regard of waste utilization

Tailings of mineral treatment are almost not applicable and hazardous to store, yet their rational use can provide great economic efficiency [6-8].

Man-made deposits result from changed requirements to marketable ores, selective extraction of rich deposit sites and increased volumes of pillars under complicated conditions of filling voids with consolidating mixtures [9$10]$.
The volume of reprocessed mineral wastes does not exceed a few percent of the total mineral output. It is explained by the fact that technologies applied do not enable extracting useful components from waste materials. Currently, each technology of ore mining and processing is characterized by some economically reasonable limits of extraction conditioned by mining parameters [11-13].

This approach complicates sustainable use of natural resources and cannot be changed at present. Methods of control intended to improve resource use and decrease man-made wastes can solve the mentioned problems [1417].

Intensive development of mining and metallurgical complexes results in accumulation of considerable amount of wastes, more than half of which is produced by the mining industry [12, 18-20]. Many scientific works deal with technological solutions of waste utilization problems [21-24].

At the same time, the degree of efficiency of utilized wastes is extremely low [25-26]. Only $15 \%$ of large ore deposits consider mining and treatment wastes as part of their technological cycle. Industrial wastes are mostly used as construction materials and to manufacture consolidating mixtures.

According to modern ideas, wastes can include natural, man-made and natural-technogenic resources (pillars). Man-made deposits are formed without considering their subsequent reuse. Although, there are some man-made deposits designed to ensure certain technological, geomechanical and physical-mechanical

\footnotetext{
* Corresponding author: morkunv@gmail.com
} 
parameters necessary for their future re-treatment.

Mining and processing enterprises can be waste-free only if issues of extracting minerals from the Earth's interior and valuable components from natural and manmade mineral materials are considered as a single technological complex and the Earth surface preservation becomes a priority in determining parameters of process integration.

In mining, complex waste utilization provides for deep re-treatment of man-made materials accompanied by extracting gold, platinum, palladium, silver, nonmagnetic hematite and other useful components as well as removing heavy metals and radionuclides to meet sanitary requirements (Fig. 1).

In developed industrial countries, utilization of industrial wastes reaches $70 \%$. In the USA, for example, $20 \%$ of aluminum, $33 \%$ of iron, $50 \%$ of lead and zinc and $44 \%$ of copper are produced as a result of re-processing mine wastes. In the state of Montana (USA), $2 \mathrm{t}$ of gold and $4 t$ of silver are obtained annually at waste dumps with $0.84 \mathrm{~g} / \mathrm{t}$ of gold and $2.8 \mathrm{~g} / \mathrm{t}$ of silver content. In Michigan (USA), $60 \%$ of copper is extracted from mill tailings with $0.3 \%$ copper content [1-3, 20-24].

Every year, in the RSA, $3.5 \mathrm{t}$ of gold and $700 \mathrm{t}$ of uranium are produced at waste dumps of gold mining mills with $0.53 \mathrm{~g} / \mathrm{t}$ gold and $40 \mathrm{~g} / \mathrm{t}$ uranium content, average productivity making $50000 \mathrm{t} /$ day. The same trend is observed in Canada, Great Britain, Spain and other countries [11,20-24].

When recycling industrial wastes, the cost of marketable products is $10-15$ times less than those produced by conventional methods. Therefore, development of this trend can result in profits comparable with basic production [27-30]. For instance, recycling 150 million ton of concentration wastes of manganese ores of Nikopol region and 500 million t of concentration wastes of Kryvyi Rih iron ores can result in manufacturing products that worth 5-7 billion USD. To update tailings recycling, there are used methods of magnetic, gravity and electrochemical separation and concentration of off-grade materials. They allow extracting such basic waste components as iron, manganese, titanium, sulphur and silica by applying magnetic separation and sorting them into selective marketable products, thus making separation and concentration of the rest waste materials by gravity methods highly effective [12-15].

Electromagnetic separation, flotation, gravity and other methods are applicable to concentrating industrial wastes and semi-finished products of steel mills [31-34]. For instance, flotation of copper and nickel is used at many national and foreign enterprises; pneumatic treatment of clinker - at some national enterprises; flotation of acid agglomerated cake resulting from cinder leaching - at zinc producing mills of Risdon (Australia), Kosaka (Japan) and Trail (Canada); retort residue jigging - at the mill of Fridrich-August (Germany).

Conventional concentration technologies have some extraction limits resulting in tailings that become unfit for further use.

Mining conditions tend to deteriorate nowadays. Prospects of the mining industry and environmental safety should be assessed considering the fact that demands for mining products are difficult to satisfy in spite of new deposits being developed.

Mineral treatment implies that from $30-40 \%$ to $99.9 \%$ of mined rock mass will turn into tailings. While expansion of tailings ponds result in destroyed vegetation and soils, increased height of tailings causes favorable conditions for dust dissemination and contamination of the biosphere of nearby areas. $20 \%$ of claim areas are occupied by rock piles, $13 \%$ - by tailings ponds of concentration plants, $5 \%$ - by dumps and wastes and $3 \%$ are turned into unfit for further use because of disturbed surface. About 0.1 ha of farming lands per $1000 \mathrm{t}$ of raw materials is expropriated for waste disposal [1-2,11].

Almost all mineral deposits are located in areas of seismic activity. Tens and hundreds cubic meters of unfilled voids are created as a result of mining operations. The voids react to geodynamic and seismic changes in the region and can cause similar changes by themselves. Seismic safety of rock mass is a system of controlling the risks caused by seismic oscillations of various intensity in a given period of time.

Modern technologies preserving the lithosphere are based on principles of protecting the Earth's surface from disruption caused by mining operations thanks to controlling geomechanical balance of the rock mass in the course of mineral extraction and any time after it. They provide filling voids with consolidating mixtures and tailings of leaching metals from ores in situ.

The influence of mining on the Earth lithosphere is determined by sizes of mine fields and workings, areas of undermining, extraction volumes and the ratio of broken rock mass to the hoisted one.

Rich ore reserves localized in favorable conditions are not sufficient. Therefore, deeper levels of existing mines and former reserve deposits with complicated mining and geological conditions are going to be developed in the nearest future. It is associated with reduced metal content in mined ores, increased volume of waste materials and augmented load on the environment [12, 16-17].

Currently, mining production is characterized by scarce mineral reserves and escalated nature-man relationship. That is why, in choosing an efficient design, environmental damage and mineral losses in situ should be taken into account.

Accumulated tailings are caused by application of mechanical energy only in the majority of traditional technologies of concentration and metallurgy. Chemical leaching in percolators does not increase metal extraction, yet it takes longer time. Leaching in a disintegrator has recently appeared as a new technology [35].

Problem statement of the research is substantiation and analysis of the suggested technology of metal leaching in the disintegrator, which is aimed at integrated application of tailings of metalliferous ores concentration.

\section{Materials and methods}

Activation of a substance by great mechanical energy under the processing speed of more than $250 \mathrm{~m} / \mathrm{sec}$ in the disintegrator results in electrically unbalanced charged centers in the material, thus radically changing mineral 
properties. The mechanochemical technology enables production by $30 \%$ cheaper, saving $30 \%$ of energy.

This trend is unique and opens up potential for revolutionary changes in ore treatment, modern information technologies ensuring its advantages by:

- application of computer-aided methods to control parameters of a process;

- versification of design variants;

- development of calculations and machine-language programs;

- development of simulation design complexes.

Efficiency of the mechanochemical technology can be proven experimentally. The first step of its substantiation is formalization of experiment requirements.

The following variants of extracting metals from mill tailings of various ores are compared: basic agitation leaching; agitation leaching after activation in the disintegrator; leaching in the disintegrator.

While conducting an experiment according to Venken-Box mathematical planning, the following independent factors are determined: sulfuric acid content in the solution $\left(\mathrm{X}_{1}\right)$ of 2-6-10 $\mathrm{g} / \mathrm{l}$; sodium chloride content in the solution $\left(\mathrm{X}_{2}\right)$; ratio of the leaching solution mass and that of tailings $\left(\mathrm{X}_{3}\right)$; time of leaching $\left(\mathrm{X}_{4}\right)$ within 0.15 $0.625-1.0 \mathrm{~h}$.

Tailings of complex ores of Sadon deposit (the Republic of North Ossetia - Alania) contain, \%: zinc 0.95 ; lead - 0.84; silver - 0.015; copper - 0.18; manganese - 0.015, etc. Reagent leaching in the disintegrator results in almost similar extraction of metals as compared to separate activation in the disintegrator, yet it reduces the process duration by 2 orders of magnitude. In the decreasing order, the process is affected by the reagent content in the leaching solution, disintegrator RPM, the number of treatment cycles, and mass ratio of the leaching solution and tailings.

Regression analysis of the research results provides the following mathematical models:

$$
\begin{array}{r}
\varepsilon=a_{0}+a_{1} X_{1}+a_{2} X_{2}+a_{3} X_{3}+a_{4} X_{4}+ \\
+a_{5} X_{12}+a_{6} X_{22}+a_{7} X_{32}+a_{8} X_{42}+a_{9} X_{1} X_{3}+ \\
+a_{10} X_{1} X_{4}+a_{11} X_{2} X_{3}+a_{12} X_{2} X_{4}+a_{13} X_{3} X_{4},
\end{array}
$$

where $X_{1}$ is $\mathrm{H}_{2} \mathrm{SO}_{4}$ content in the leaching solution, $\mathrm{g} / \mathrm{l} ; X_{2}$ is $\mathrm{NaCl}$ content in the leaching solution, $\mathrm{g} / \mathrm{l} ; X_{3}$ is the ratio of solid and liquid phases; $X_{4}$ is RPM of the disintegrator, $\mathrm{Hz}$.

The determination factor for the zinc extraction dependency makes $R_{2}=0.85851$, for lead extraction dependency $R_{2}=0.78037$, for iron extraction dependency $R_{2}=0.94587$.

To achieve objective assessment of changes in dependencies, the graphic-analytical method is applied. To present changes of extraction values of larger groups of metals, there are diagrams of dependencies of metal extraction on each predictor, while the values of the three left predictors are averaged, i.e. for $X_{1}=6 \mathrm{~g} / 1, X_{2}=90 \mathrm{~g} / \mathrm{l}$, $X_{3}=7, X_{4}=125 \mathrm{~Hz}$ (Fig. 2-5).

The dependencies are continuous and are characterized by flex and extremum points in the diagram indicating accuracy of mechanochemical activation for leaching metals in the disintegrator. Dependencies between studied parameters of multi-grade materials and indices of metal extraction can be used to find optimal parameters in solving optimum problems by IT methods.

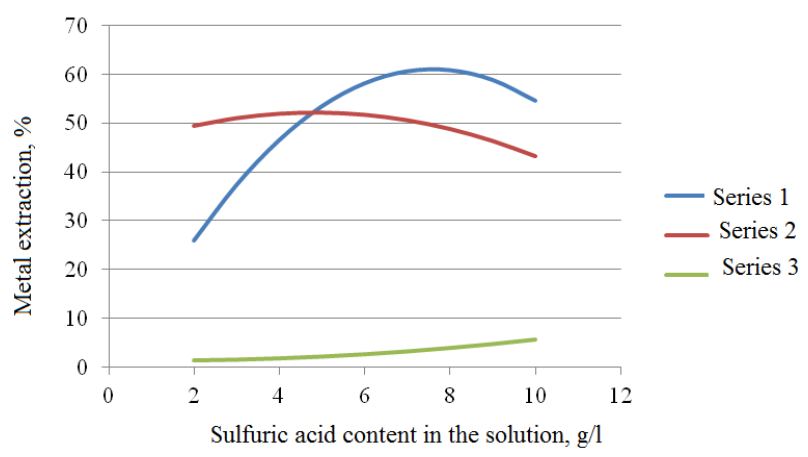

Fig. 2. Dependency of metal extraction in the solution on sulfuric acid content in the leaching solution:

Series 1 is zinc extraction $\varepsilon=-1.1144 X_{12}+16.942 X_{1}-3.4359$; Series 2 is lead extraction $\varepsilon=-0.3352 X_{12}+3.2464 X_{1}+44.31$; Series 3 is iron extraction $\varepsilon=0.0529 X_{12}-0.115 X_{1}+1.4897$.

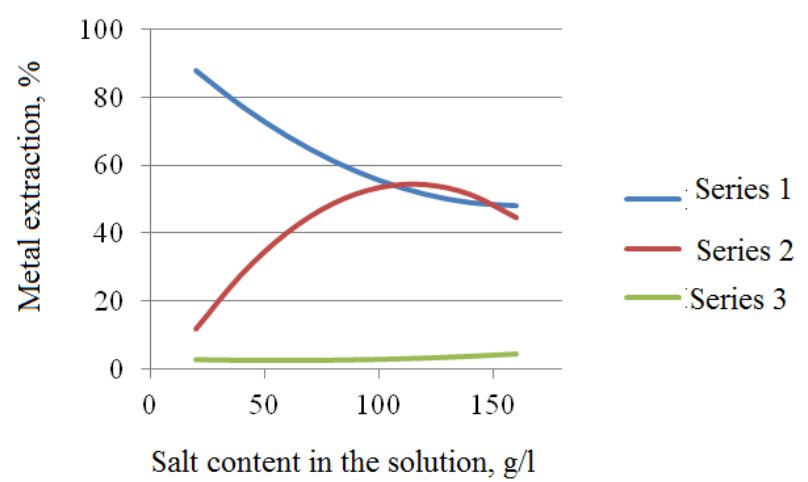

Fig. 3. Dependency of metal extraction in the solution on salt content in the leaching solution: Series 1 is zinc extraction $\varepsilon=0.002 X_{22}-0.6422 X_{2}+99.776$; Series 2 is lead extraction $\varepsilon=-0.0048 X_{22}+1.0994 X_{2}-8.345$; Series 3 is iron extraction $\varepsilon=0.0002 X_{22}-0.0222 X_{2}+3.14$.

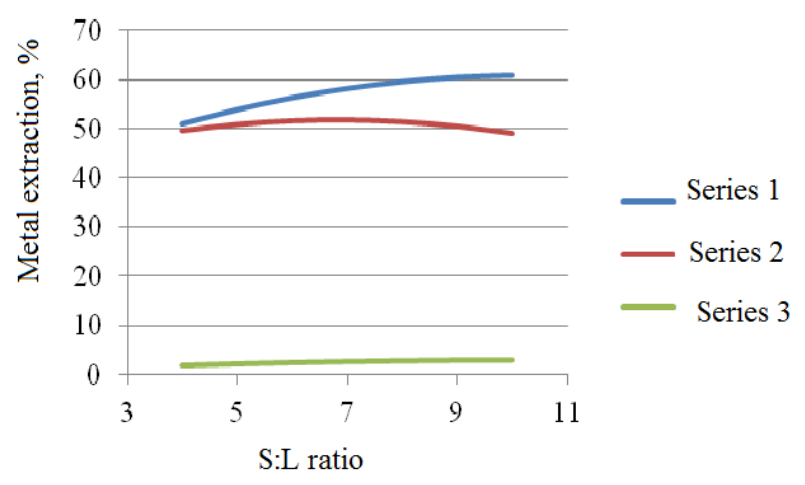

Fig. 4. Dependency of metal extraction on the ratio of solid and liquid phases:

Series 1 is zinc extraction $\varepsilon=-0.2466 X_{32}+5.062 X_{3}+34.75$; Series 2 is lead extraction $\varepsilon=-0.2603 X_{32}+3.5523 X_{3}+39.61$; Series 3 is iron extraction $\varepsilon=-0.0282 X_{32}+0.5917 X_{3}-0.0553$.

\section{Results and discussion}

The developed concept of waste-free treatment of offgrade mineral materials includes the following principles: 
1. Conventional concentration does not provide full exposure of minerals and cannot be applied to deep extraction of minerals from mill tailings.

2. There is a promising trend of improving extraction of minerals from off-grade mineral materials by combining chemical leaching and mechanical activation in the disintegrator where the leaching solution is pressed into formed cracks facilitating the extraction rate which is inaccessible for traditional technologies.

3. Parameters of mechanochemical leaching of components from metal-bearing raw materials are subjected to forecasting on the basis of experiments by unified methods of formalizing requirements.

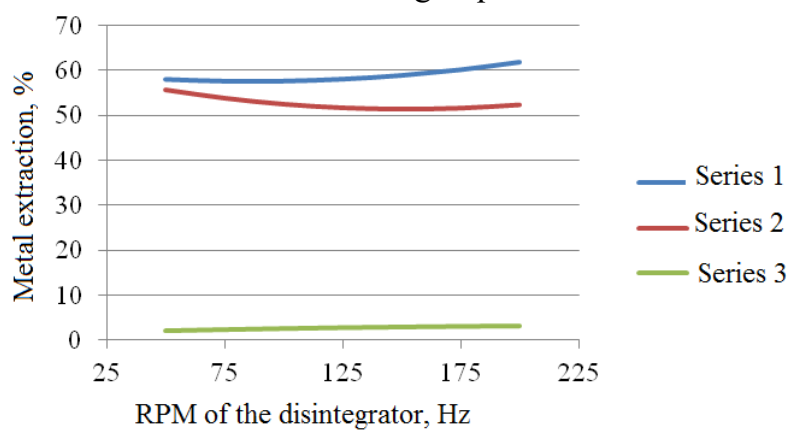

Fig. 5. Dependency of metal extraction on intensity of mechanical activation or RPM of the disintegrator:

Series 1 is zinc extraction $\varepsilon=0.0003 X_{42}-0.0555 X_{4}+60.038$;

Series 2 is lead extraction $\varepsilon=0.0004 X_{42}-0.1215 X_{4}+60.658$;

Series 3 is iron extraction $\varepsilon=-0.00002 X_{42}+0.0122 X_{4}+$ 1.5468 .

Environmental and economic efficiency of the modern mining complex should be characterized by minimal material, energy and other expenses to produce marketable products and prioritize preservation of ecosystems and sustainable mineral use. When determining profitability of mineral mining, one should consider mined resources that are not turned into marketable products and become lost.

The model of efficient use of off-grade mineral materials contained in mill tailings looks like [13]:

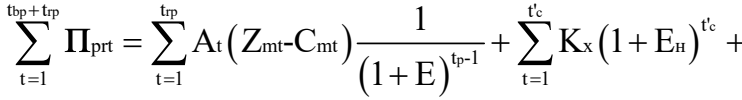

$$
\begin{aligned}
& +\gamma_{\mathrm{x}}\left[\sum_{\mathrm{t}=1}^{\mathrm{tpp}} \mathrm{A}_{\mathrm{pt}}\left(\mathrm{Z}_{\mathrm{mrt}}-\mathrm{C}_{\mathrm{mrt}}\right)-\sum_{\mathrm{t}=1}^{\mathrm{t} p \mathrm{p}} \mathrm{K}_{\mathrm{dat}}\left(1+\mathrm{E}_{\mathrm{c}}\right)^{\mathrm{t} \mathrm{p}}\right],
\end{aligned}
$$

where $\gamma_{\mathrm{x}}$ is the yield of off-grade materials, unit fraction; $A_{t}$ is production capacity of an enterprise in the $t$-th year, $t /$ year; $t_{r p}$ is a rated period of application of a technical design, years; tpba is a period of building auxiliary facilities for re-treatment, years; $t^{\prime} c$ is a period of construction, years; $Z_{\mathrm{mt}}$ and $\mathrm{C}_{\mathrm{mt}}$ are the extracted value of mined rock mass and expenses for mining and processing in the $t$-th year, $\mathrm{UAH} / \mathrm{t}$; $\mathrm{K}_{\mathrm{xt}}$ construction investments in the $t$-th year, $\mathrm{UAH}$; $\mathrm{A}_{\mathrm{pt}}$ is production capacity of an enterprise for off-grade materials retreatment in the $t$-th year, $\mathrm{UAH} / \mathrm{t} ; \mathrm{Z}_{\mathrm{mrt}}$ and $\mathrm{C}_{\mathrm{mrt}}$ are the value extracted from off-grade materials and re-treatment costs in the $t$-th year, $\mathrm{UAH} / \mathrm{t} ; K_{\mathrm{dat}}$ is expenses for constructing and developing auxiliary facilities in the $t$-th year, UAH; $\mathrm{E}$ is the factor of discounting expenses and profits in terms of time, unit fraction; $E_{c}$ is a bank-credit interest for performing auxiliary operations, unit fraction.

The environmental and economic model of efficiency of off-grade materials re-treatment by the maximum profit criterion and considering the region environment is the following:

$$
\begin{aligned}
& \Pi=\sum_{\mathrm{p}=1}^{\mathrm{P}} \sum_{\mathrm{o}=1}^{\mathrm{O}} \sum_{\mathrm{r}=1}^{R} \sum_{\mathrm{t}=1}^{\mathrm{T}} \sum_{\mathrm{f}=1}^{\mathrm{F}} \sum_{\mathrm{n}=1}^{\mathrm{N}}\left\{\left(\mathrm{M}_{\mathrm{ey}} \mathrm{Z}_{\mathrm{my}}+\mathrm{Q}_{\mathrm{y}} \mathrm{Z}_{\mathrm{qy}}\right)\right\}- \\
& -\sum_{w=1}^{W}\left[\mathrm{~K}\left(1+\mathrm{E}_{\mathrm{ny}}\right)+\mathrm{E}_{\mathrm{q}}+\mathrm{E}_{\mathrm{x}}\right]- \\
& -\left[\left(\mathrm{M}_{\mathrm{e}} \mathrm{Z}_{m}+\mathrm{QZ}_{\mathrm{q}}\right)+\mathrm{Q}_{\mathrm{g}} \mathrm{Z}_{\mathrm{g}}\right] \times \\
& \times \mathrm{K}_{\mathrm{c}} \mathrm{K}_{\mathrm{y}} \mathrm{K}_{t} \mathrm{~K}_{\mathrm{b}} \mathrm{K}_{\mathrm{g}} \mathrm{K}_{v r} \mathrm{~K}_{c h} \rightarrow \max
\end{aligned}
$$

where $\mathrm{P}$ is utilization products; $\mathrm{Q}$ is types of off-grade materials; $\mathrm{R}$ is re-treatment processes of off-grade materials; $\mathrm{T}$ is re-treatment time; $\mathrm{F}$ is phases of existence of a mine and a plant; $\mathrm{N}$ is a stage of off-grade material utilization; $\mathrm{W}$ is expenses for off-grade materials utilization; $\mathrm{K}$ is capital investments for arranging a utilization site; $K_{c}$ is a self-organization factor of off-grade material storages.

The mathematical model of leaching metals from ores correlates to conditions and technological features of metal extraction described by regression dependencies and subjected to forecasting.

The complex composition of mill tailings containing the first and the second hazard class substances does not enable their utilization without waste neutralization. Available technologies of re-treatment cannot extract valuable components under their low content to meet required sanitary standards.

Tailings re-treatment can make the need to store utilized tailings on the surface redundant and corresponding lands can be returned into farming use [36].

Metal-bearing tailings can be re-treated only in case of metal extraction according to sanitary standards. Mechanochemical re-treatment is able to meet these requirements. Tailings of mechanochemical activation of mill wastes are a dispersed mass of particles about $0.1 \mathrm{~mm}$ in size noted for a more uniform structure, which facilitates re-treatment quality.

In re-treatment of man-made deposits, there are used off-grade reserves, the amount of which is comparable with initial reserves of large deposits. If there are available capacities to utilize off-grade materials, it becomes efficient as expenses for their retreatment are already amortized.

The economic effect of developing man-made deposits includes increased extraction of metals with minimal production expenses and re-treatment stages to obtain a marketable product.

The maximum economic effect of introducing innovative technologies is achieved due to increased mineral reserves, production conversion and extended life-cycles of deposits.

To compare technologies with different mineral extraction rates, it is necessary to assess losses of minerals in comparable units of measurement. When evaluating 
losses, it is reasonable to analyze the lost value of components determined by the limit prices of the industry. It enables the single criterion of the technology - profits allowing for damage by mineral losses both in situ and tailings.

Putting wastes of no industrial use into operation has a great impact on the amount of extracted reserves and metal content of the mined ore, thus reducing operational costs and improving efficiency of investments and production assets.

Elimination of the need to store tailings on the Earth's surface can ensure profits by selling re-treatment products, returning lands into economic use and improving the region's environment.

\section{Conclusions}

Metal-bearing mine wastes accumulated on the Earth's surface present a global problem that can be solved by their utilization which turns hazardous off-grade materials into a valuable resource.

Human demands in metals can be satisfied by using concentration tailings as a new raw material base of the mining industry, thus solving the problem of deficiency of some metals. Substantiation of the concept of the waste-free re-treatment of off-grade mineral materials depends on combining chemical leaching and mechanochemical activation in the disintegrator treated as a single technological cycle.

Scientific novelty is that for the first time, the method of improving efficiency of the technology of leaching metals from the currently substandard mineral materials through combining chemical leaching and mechanical activation in the disintegrator where the leaching solution is pressed into the cracks resulted from particle destruction has been substantiated, this providing for efficient speed of recovery impossible under the traditional technology.

There are three variants of recovery of metals from ore concentration tailings of various types: basic agitation leaching, agitation leaching after activation in the disintegrator and leaching in the disintegrator.

It is demonstrated that in comparison with separate activation in the disintegrator and leaching outside the disintegrator, reagent leaching in the disintegrator provides almost the same metal recovery, yet it reduces duration of the process by two orders of magnitude. It is determined that the process is affected by the following factors in the descending order: reagent content in the leaching solution, rotor frequency in the disintegrator, the number of processing cycles in the disintegrator and the mass ratio of the leaching solution and tailings.

The regression analysis of the experiment results provides for mathematical dependencies of metal recovery on the content of $\mathrm{H}_{2} \mathrm{SO}_{4}$ and $\mathrm{NaCl}$ in the leaching solution, liquid-solid phase ratio, and rotor frequency of the disintegrator. The determination factor for the zinc recovery dependency makes $R^{2}=0.85851$, that of lead recovery is $R^{2}=0.78037$, and that of iron recovery is $R^{2}=0,94587$.

\section{References}

1. M. E. Jarvie-Eggart, Responsible mining: case studies in managing social and environmental risks in the developed world (Englewood, Colorado, 2015)

2. A. Jordens, Y.P. Cheng, K.E. Waters, A review of the beneficiation of rare earth element bearing minerals. Miner. Eng. 41, 97-114 (2013). doi:10.1016/j.mineng.2012.10.017

3. H. Wang, Y. He, C. Duan, Y. Zhao, Y. Tao, C. Ye, Development of mineral processing engineering education in China University of Mining and Technology. Advances in Comp. Sci. and Eng. 141, 77-83 (2012). doi:10.1007/978-3-642-27948-5_11

4. M.B. Fedko, V.A. Kolosov, S.V. Pismennyi, Ye.V. Kalinichenko, Economic aspects of change-over to TNT-free explosives for the purposes of ore underground mining in Kryvyi Rih basin. Naukovyi Visnyk Natsionalnoho Hirnychoho Universytetu 4, 79-84 (2014). doi:10.31721/2306-5451-2018-1-46$81-85$

5. M.I. Stupnik, V.O. Kalinichenko, S.V. Pysmennyi, O.V. Kalinichenko, Determining the qualitative composition of the equivalent material for simulation of Kryvyi Rih iron ore basin rocks. Naukovyi Visnyk Natsionalnoho Hirnychoho Universytetu 4, 21-27. (2018). doi:10.29202/nvngu/2018-4/4

6. V. Golik, V. Komashchenko, V. Morkun, Geomechanical terms of use of the mill tailings for preparation. Metallurg. and Mining Ind. 7(4), 321324 (2015)

7. V. Golik, V. Komashchenko, V. Morkun, O. Burdzieva, Metal deposits combined development experience. Metallurg. and Mining Ind. 7(6), 591594 (2015)

8. V. Morkun, N. Morkun, V. Tron, S. Hryshchenko, O. Serdiuk, I. Dotsenko, Basic regularities of assessing ore pulp parameters in gravity settling of solid phase particles based on ultrasonic measurements. Arch. of Acoust. 44(1), 161-167 (2019). doi:10.24425/aoa.2019.126362

9. S. Pysmennyi, D. Brovko, N. Shwager, I. Kasatkina, D. Paraniuk, O. Serdiuk, Development of complexstructure ore deposits by means of chamber systems under conditions of the Kryvyi Rih iron ore field. East.-European J. of Enterprise Tech. 5, 1(95), 33-45 (2018). doi:10.15587/1729-4061.2018.142483

10. V. Kalinichenko S. Pysmennyi N. Shvaher, O. Kalinichenko, Selective underground mining of complex structured ore bodies of Kryvyi Rih Iron Ore Basin. E3S Web of Conf. 60, 00041 (2018). doi:10.1051/e3sconf/20186000041

11. G.I. Gazaleyeva, S.B. Mamonov, Ye.V. Bratygin, A.M. Klyushnikov, Problems and innovative solutions in technogenic materials concentration. GIAB 1, 257-272 (2017)

12. V.I. Komashenko, I.V. Erohin, Concept of reducing hazardous contamination of the mining regions of 
KMA. Mining inform. and analisys bull. 2, 10-16 (2014)

13. J.M. Harris, B. Roach, M. E. Sharpe, Environmental and natural resource economics. A contemporary approach (Armonk, New York, 2013)

14. A. Kupin, D. Kuznetsov, I. Muzyka, D. Paraniuk, O. Serdiuk, O. Suvorov, V. Dvornikov, The concept of a modular cyberphysical system for the early diagnosis of energy equipment. East.-European J. of Enterprise Technol. 4 (2-94), 71-79 (2018). doi:10.15587/1729-4061.2018.139644

15. S. Tishchenko, G. Eremenko, O. Kukharenko, A. Pikilnyak, I. Gaponenko, Definition of the destruction zone boundaries and particle size distribution of blasted rock mass in the explosion of a single explosive charge in an inorganic medium. Metallurg. and Mining Ind. 7(8), 564-567 (2015)

16. A. Bublikov, V. Tkachov, Automation of the control process of the mining machines based on fuzzy logic. Naukovyi Visnyk Natsionalnoho Hirnychoho $\begin{array}{llll}\text { Universytetu } & 3, & 112-118 & \text { (2019). }\end{array}$ doi:10.29202/nvngu/2019-3/19

17. I. Kotov, O. Suvorov, O. Serdiuk, Development of methods for structural and logical model unification of metaknowledge for ontologies evolution managing of intelligent systems. East.-European J. of Enterprise Technol. 2(4-98), 38-47 (2019). doi:10.15587/17294061.2019.155410

18. V.I. Lyashenko, V.P. Franchuk, B.P. Kislyi, Modernization of the technical and technological complex of uranium mining. Mining J. 1, 26-32 (2015)

19. V.I. Komashchenko, P.V. Vasilyev, S.A. Maslennikov, Reliable raw material base of underground mining of KMA deposits. Izvestiya TulGU. Earth Sciences 2, 95-101 (2016)

20. J. Liu, Y. Han, Y. Li, S. Zhang, Study on mechanism and technology of deep reduction for iron ore leaching, in The 26th International Mineral Processing Congress, IMPC 2012: Innovative Processing for Sustainable Growth, New Delhi, 2428 September 2012

21. A.G. Sekisov, Yu.S. Shevchenko, A.Yu. Lavrov, Prospects of mine leaching in mining gold ore deposits. FTPRRMPI 1, 110-116 (2016)

22. M. Minagawa, S. Hisatomi, T. Kato, G. Granata, C. Tokoro, Enhancement of copper dissolution by mechanochemical activation of copper ores: Correlation between leaching experiments and DEM simulations. Adv. Powder Technol. 29(3), 471-478 (2018). doi:10.1016/j.apt.2017.11.031

23. D. Zhang, H. Ling, T. Yang, W. Liu, L. Chen, Selective leaching of zinc from electric arc furnace dust by a hydrothermal reduction method in a sodium hydroxide system. J. of Cleaner Prod. 224, 536-544 (2019). doi:10.1016/j.jclepro.2019.03.149

24. H. Xie, L. Zhang, H. Li, S. Koppala, S. Yin, S. Li, K. Yang, F. Zhu, Efficient recycling of $\mathrm{Pb}$ from zinc leaching residues by using the hydrometallurgical method. Mater. Res. Express. 6(7) (2019). doi:10.1088/2053-1591/ab11b9

25. Y. Khint, Uda-technology. Special designtechnological bureau Disintegrator (Valgus, Tallinn, 1981)

26. Y. Yang, X. Zheng, H. Cao, C. Zhao, X Lin., P. Ning, Y. Zhang, W. Jin, Z. Sun, A closed-loop process for selective metal recovery from spent lithium iron phosphate batteries through mechanochemical activation. ACS Sustain. Chem. \& Eng. 5(11), 99729980 (2017). doi:10.1021/acssuschemeng.7b01914.

27. S. Cetintas, U. Yildiz, D. Bingol, A novel reagentassisted mechanochemical method for nickel recovery from lateritic ore. J. of Cleaner Prod. 199, 616-632 (2018). doi: 10.1016/j.jclepro.2018.07.212.

28. E. Fan, L. Li, X. Zhang, Y. Bian, Q. Xue, J. Wu, F. $\mathrm{Wu}, \mathrm{R}$. Chen, Selective recovery of $\mathrm{Li}$ and $\mathrm{Fe}$ from spent lithium-ion batteries by an environmentally friendly mechanochemical approach. ACS Sustain. Chem. \& Eng., 6(8), 11029-110315 (2018). doi:10.1021/acssuschemeng.8b02503

29. M. Wang, Q. Tan, J. Li, Unveiling the role and mechanism of mechanochemical activation on lithium cobalt oxide powders from spent lithium-ion batteries. Environ. Sci. \& Technol., 52(22), 1313613143 (2018). doi: 10.1021/acs.est.8b03469.

30. Y. Ghorbani, J.-P. Franzidis, J. Petersen, Heap leaching technology - current State, innovations, and future directions: a review. Miner. Proc. and Extract. Metall. Rev. 37(2), 73-119 (2016). doi:10.1080/08827508.2015.1115990

31. G. Granata, K. Takahashi, T. Kato, C. Tokoro, Mechanochemical activation of chalcopyrite: Relationship between activation mechanism and leaching enhancement. Miner. Eng. 131, 280-285 (2018). doi:10.1016/j.mineng.2018.11.027.

32. L. Sinclair, J. Thompson, In situ leaching of copper: Challenges and future prospects. Hydrometallurgy, 157, 306-324 (2015). doi:10.1016/j.hydromet.2015.08.022

33. D.M. De Oliveira, L.G.S. Sobral, G.J. Olson, S.B. Olson, Acid leaching of a copper ore by sulphuroxidizing microorganisms. Hydrometallurgy 147148, 223-227 (2014). doi:10.1016/j.hydromet.2014.05.019

34. A.A. Morozov, M.V. Yakovlev, Processing of offbalance uranium ores formed in mining Streltsovo ore deposit. GIAB 12, 174-181 (2016)

35. A.M. Freeman, J.A. Herriges, C.L. Kling, The measurement of environmental and resource values. Theory and methods (RFF Press, New York, 2014)

36. V.I. Lyashenko, Environment-saving technologies for mining complex deposits. Mine-Surv. J., 1, 10-15 (2015) 